\title{
A rare gastric lesion: Russel body gastritis
}

\author{
Mehmet Suat Yalçın ${ }^{1}$, Melike Ordu \\ ${ }^{1}$ Department of Gastroenterology, Aksaray Education and Research Hospital, Aksaray, Turkey \\ ${ }^{2}$ Department of Pathology, Aksaray Education and Research Hospital, Aksaray, Turkey
}

Gastroenterology Rev 2020; 15 (3): 273-274

DOI: https://doi.org/10.5114/pg.2020.98536

Address for correspondence: Mehmet Suat Yalçın MD, Department of Gastroenterology, Aksaray Education and Research Hospital, Aksaray, Turkey, phone: +90 5305757496, e-mail: drsuat02@hotmail.com

Russell body gastritis was first described by Tazawa and Tsutsumi, and it is a very rare medical condition. Russell body gastritis is a condition in which the lamina propria of the gastric mucosa are over-infiltrated by plasma cells containing Russell bodies, which are eosinophilic intracytoplasmic inclusions. Yu et al. reported a similar case in South Korea in 1987, which was not described as Russell body gastritis at the time. There are very few case reports in the literature. Some of them have been associated with Helicobacter pylori infection. However, it has been reported in HIV-positive cases that are not due to $H$. pylori.

We aimed to present a case of Russel body gastritis diagnosed by biopsy taken with suspicion of gastric premalignant lesion in our clinic.

A 55-year-old male patient was admitted to our clinic with complaints of nausea, epigastric pain, and indigestion. Physical and laboratory examinations were normal. Upper gastrointestinal endoscopy revealed diffuse hyperaemic, oedematous, and nodular erosions in the antrum of the entire gastric mucosa. Biopsies were taken from the lesions in the antrum (Figure 1). Histological examination revealed chronic gastritis and Mott cells in the lamina propria. Russel body gastritis was reported. Mott cells were positive for CD138 and negative for pancreatin. $\kappa$ and $\lambda$ light chains showed that they originated in a polyclonal plasma cell (Figure 2). Antrum biopsy materials was positive for $\mathrm{H}$. pylori infection with Giemsa stain. Helicobacter pylori eradication therapy was performed according to guidelines. Endoscopic follow-up and controls were planned after the treatment.

In 1890, for the first time, Russell bodies were identified [1]. These bodies occur as a result of abnormal functioning of immunoglobulin secretion pathways in plasma cells [2]. These plasma cells are referred to as Mott cells. These cells may occur in the gastric mucosa due to chronic inflammation. Mott cells can also be seen in some diseases such as ulcerative colitis, malig- nant lymphoma, Hashimoto's thyroiditis, rheumatoid arthritis, and malignant plasmacytoma [2, 3]. In 1998, Tazawa and Tsutsumi used the term Russell body gastritis for the first time, when they reported the accumulation of plasma cells containing Russell bodies secondary to $H$. pylori infection [1]. The cause of localised accumulation of plasma cells is not clear. However, it has been suggested that chronic antigenic stimulation caused by $H$. pylori infection may be a cause. However, cases of Russell body gastritis that are HIV positive and $H$. pylori negative have also been reported in the literature $[4,5]$. It is a disease that mostly affects women [4]. Most patients present with non-specific gastrointestinal symptoms. These symptoms include abdominal pain, dyspepsia, and nausea. Like these symptoms, the endoscopic image of Russell body gastritis is not specific. Fluffy nodules can sometimes be seen in the gastric mucosa [2]. Biopsies of the gastric mucosa should be performed for diagnosis. Russell body gastritis is a disease diagnosed with histopathological findings. Histopathologically, the diagnosis is confirmed by an excessive number of Mott cells in the gastric mucosa.

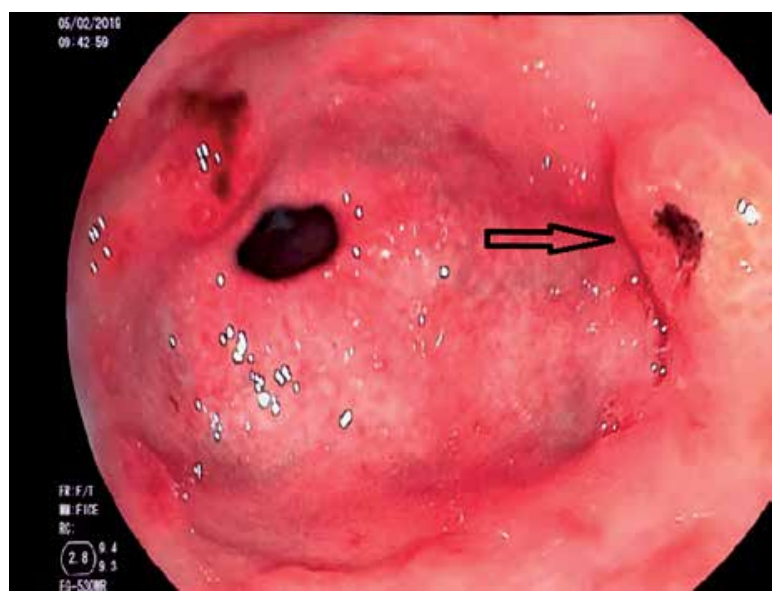

Figure 1. Endoscopic image 

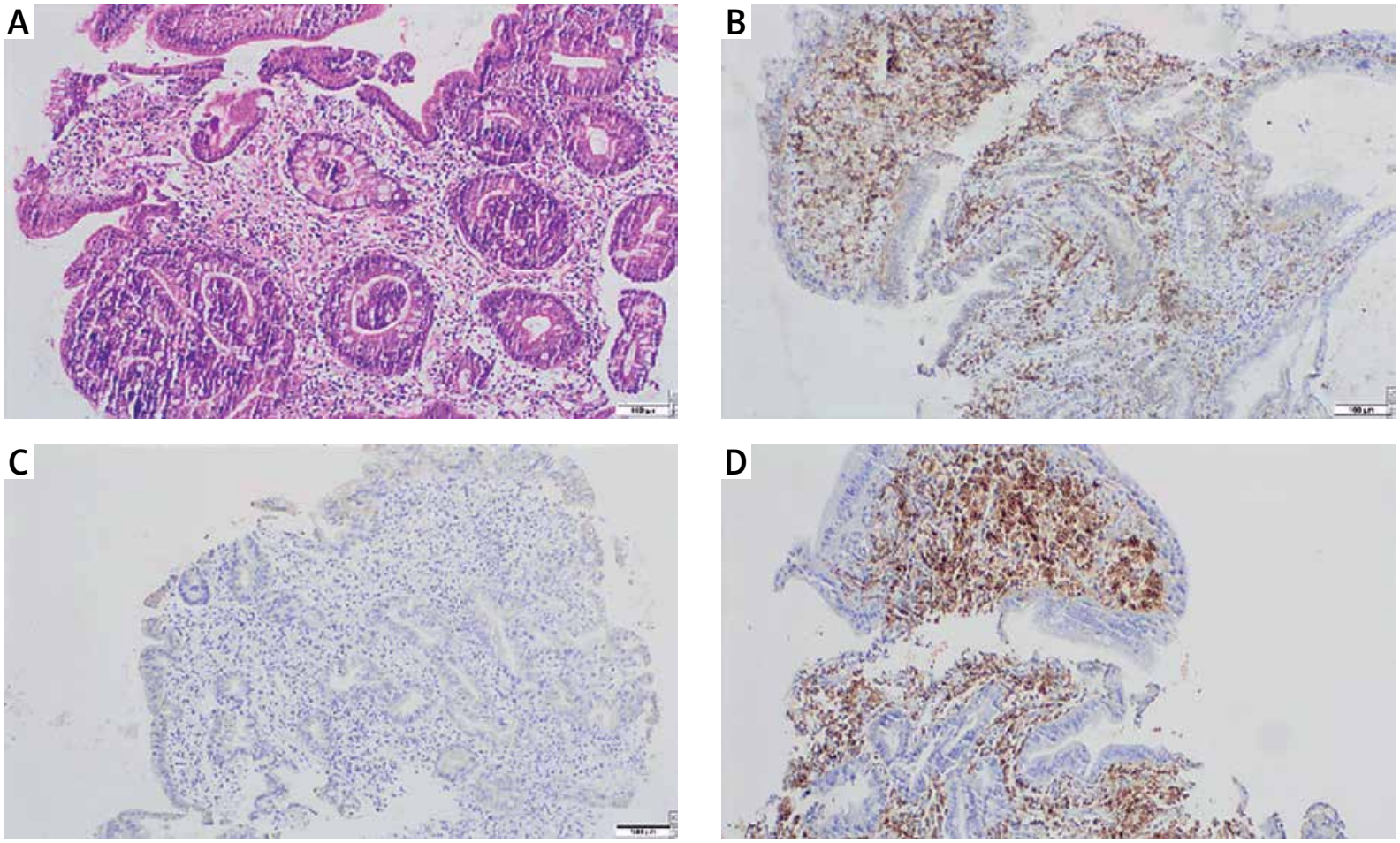

Figure 2. Histopathological findings. A - Mott cells. B - CD 138. C, D $-\kappa$ and $\lambda$ chain

In differential diagnosis, other Mott cell diseases should be excluded. Cytokeratin negativity on histopathological examination excludes carcinoma. $\kappa$ and $\lambda$ polyclonal immunoreactive pattern excludes plasmacytoma and MALToma as a diagnosis [6]. Some Russell body gastritis cases show similar features endoscopically to gastric xanthoma. Histopathological examination is necessary to confirm the differential diagnosis. Other causes of Russell body gastritis include infectious agents, ethanol use, and gastric cancer [7]. The most common antrum involvement is reported. In addition, $H$. pylori was positive in more than $70 \%$ of cases. After $\mathrm{H}$. pylori treatment, it was found that $80 \%$ of the cases recovered [1]. It has been reported that Russell bodies are more common in normal tissues surrounding malignant lesions and may reflect the possibility of a relationship between malignancy and Russell body gastritis [8].

In our case, Mott cells were stained positive for CD138 and negative for pancreatin histopathologically. $\kappa$ and $\lambda$ light chains showed that they originated in polyclonal plasma cells. Thus, gastric carcinoma was ruled out. Helicobacter pylori was positive with Giemsa stain. Endoscopic erosion nodules were observed in our case. The image in terms of malignancy was met with suspicion. Because it is a rare clinical condition after pathological examination, we believe that it should be presented. Further studies and case study reports are needed for this condition, which is limited in the literature.

\section{Conflict of interest}

The authors declare no conflict of interest.

\section{References}

1. Yoon JB, Lee TY, Lee JS, et al. Two cases of russell body gastritis treated by Helicobacter pylori eradication. Clin Endosc 2012; 45: 412-6.

2. Bhaijee F, Brown KA, Long BW, et al. Russell body gastroenteritis: an aberrant manifestation of chronic inflammation in gastrointestinal mucosa. Case Rep Med 2013; 2013: 797264.

3. Paik S, Kim SH, Kim JH, et al. Russell body gastritis associated with Helicobacter pylori infection: a case report. J Clin Pathol 2006; 59: 1316-9.

4. Del Gobbo A, Elli L, Braidotti P, et al. Helicobacter pylori-negative Russell body gastritis: case report. World I Gastroenterol 2011; 17: 1234-6.

5. Bhalla A, Mosteanu D, Gorelick S, et al. Russell body gastritis in an HIV positive patient: case report and review of literature. Conn Med 2012; 76: 261-5.

6. Karabagli P, Gokturk HS. Russell body gastritis: case report and review of the literature. J Gastrointestin Liver Dis 2012; 21: 97-100.

7. Peker BC, Kirdok FS, Dizen H. Russell body gastritis: an unusually presentation of the chronic gastritis. Iran J Pathol 2016; 11: 452-5.

8. Johansen A, Sikjär B. The diagnostic significance of Russell bodies in endoscopic gastric biopsies. Acta Pathol Microbiol Scand A 1977; 85A: 245-50.

Received: 27.10 .2019

Accepted: 15.02 .2020 